Gut, 1985, 26, 656-666

\title{
Alimentary and pancreas
}

\section{Intestinal function and intestinal blood supply: a 20 year surgical study}

\author{
A MARSTON, J M F CLARKE, J GARCiA GARCIA, AND A L Miller \\ From the Department of Surgical Studies and the Courtauld Institute of Biochemistry, The Middlesex Hospital \\ Medical School, University of London, London
}

SUMmary The experience of The Middlesex Hospital in the investigation and management of chronic intestinal arterial occlusion (IAO) over a 20 year period is presented. Of some 100 patients referred only 28 were found to have IAO and these were critically evaluated in terms of insorptive and exsorptive function. No relation was found between intestinal performance and the degree of potential ischaemia suggested by angiography. Twenty two patients underwent reconstruction of the coeliac axis and mesenteric arteries, with three perioperative deaths. The remainder were followed for periods ranging between six months and 10 years. Of these, 15 are asymptomatic, one is unchanged, and one is subjectively worse. The role of elective surgery in relation to the visceral arteries is critically discussed in the light of these results, and in the perspective of the world experience.

It is known that the origins of the three main visceral arteries are frequently narrowed or blocked by atheroma, ${ }^{1-4}$ but the relationship between this lesion and the development of abnormalities in the alimentary tract remains unclear. Whereas intestinal infarction, if not relieved, is always fatal, it is not easy to identify the pre-infarctive state, which might be amenable to treatment. This study addresses the following questions: (1) Does it happen that the blood supply to the gut becomes so reduced that symptoms occur, before the point of infarction is reached, and if so, how frequently? (2) Can this situation be identified clinically, or by laboratory tests of intestinal function? (3) Given the existence of symptomatic occlusion of the visceral arteries, what is the risk of a fatal infarction occurring in the individual patient? (4) What is the role of elective surgical reconstruction of the intestinal blood supply?

The ideal way of resolving these questions would be to measure gut blood flow in a control population of normal people, and in patients with intestinal arterial occlusion (IAO), and to investigate alimen-

Address for correspondence: Mr Adrian Marston, FRCS, 82 Harley Street, London W1N 1AE.

Received for publication 20 September 1984 tary function in both groups, so as to identify any significant difference. The subjects would then be watched over a period of years, without treatment, in order to compare symptoms and eventual mortality. Obviously such a study would be both unethical and impractical. The investigator is constrained by the needs of his patients, and by considerations of money and time, quite apart from the fact that at the present moment we have no method of measuring intestinal bloodflow in the intact human being which is acceptably non-invasive. Total splanchnic blood flow can, and has been measured, ${ }^{5}$ but this is a different question, as is later discussed. The problem has to be approached indirectly, and this has been done in three ways.

\section{Methods}

\section{ANIMAL STUDIES}

The mesenteric circulation of the experimental animal has been extensively studied over the last century and this work is reviewed elsewhere. ${ }^{8}$ Much of it is probably irrelevant to human illness, but from the mass of data collected two observations stand out. ${ }^{67}$ (1) The intestine takes about one fifth of the resting cardiac output, and after a meal this 
proportion rises by about $15 \%$. (2) Chronic reduction of the blood supply to the gut does not have any discernible effect on structure or function, until infarction occurs, which brings about a catastrophic series of disturbances, leading to death.

These findings derive from methods which are at best invasive, and often lethal, and have no clinical use. It is reasonable to suggest, however, that the human gut $^{8}$ may respond in the same way as do other mammals to ischaemic insult.

\section{AUTOPSY STUDIES}

The incidence of arterial stenoses and occlusions in a given population can be determined by postmortem examination. Our group ${ }^{3}$ recently reviewed this problem and produced revised data which in the light of 203 consecutive autopsies, indicated that although minor degrees of ostial stenosis are common, 'critical stenosis' as defined by careful analysis of external and internal diameters of the visceral arteries, in relation to accepted estimates of flow, is unusual. This series (which is the largest so far reported) corrects previous data which suggested that major ostial lesions were frequent. There is a clinical parallel in that in a series of 2000 mesenteric arteriograms ${ }^{9}$ the number of identifiable stenoses was less than $5 \%$. The more interesting conclusion from our study, however, was that no relationship could be found between IAO (as seen postmortem) and symptoms of digestive disease experienced during life.

\section{CLINICAL STUDIES}

These mainly depend on arteriography. A qualitative guide to intestinal bloodflow can be made by measuring the cross sectional area of the vessels radiologically. ${ }^{1}$ Such studies have, however, never been related to intestinal function. Most surgeons reporting series of operations to restore circulation to the intestine have been content to plan treatment on the basis of angiography, and to estimate success on subjective grounds. Bearing in mind the prevalence of asymptomatic arterial lesions, ${ }^{23}$ and the placebo effect of major surgery, the indications for this type of operation, which is expensive and not without risk, remain unclear. Certainly, disturbances of function after successful revascularisation of the acutely ischaemic bowel have been studied in depth $^{8-12}$ but this is a quite different clinical situation. Whether or not the insorptive and exsorptive functions of the GI tract are affected by IAO is disputed, because some authors ${ }^{13-15}$ describe consistent abnormalities in relation to reduced blood supply, while others ${ }^{16-19}$ deny the usefulness of all such measurements.

The most direct approach to this problem has been made by Hansen's group in Denmark ${ }^{5}$ who estimated total splanchnic bloodflow (SBF) using hepatic clearance of indocyanine green, in 15 persons, distributed between four controls (that is patients with abdominal pain but no arterial lesion), five suspects (patients with abdominal pain and a minor stenosis shown radiographically) and six patients who had both symptoms and major angiographic lesions and underwent surgery. Hansen showed that resting splanchnic blood flow was comparable in all groups, but that the six identified patients were unable to increase total splanchnic flow when challenged by a meal. After reconstruction of the visceral arteries, the patient group exhibited an increased fasting flow, equivalent to the controls, and regained the capacity to expand flow after the test. Measurement of liver blood flow, however, bears an uncertain relationship to what happens in the gut. The liver receives blood via the hepatic artery (which was not studied here) and the portal vein, via the stomach, spleen, the diaphragm, and innumerable collateral pathways which expand when the normal routes of supply are blocked. What we cannot at present measure is intestinal blood flow, which is the main determinant of eventual infarction. Although Hansen's group could correlate splanchnic blood flow with later clinical performance, no operative nor long term data are included, and the authors modestly describe their important work as a preliminary study. More recently Fleming $^{20}$ has developed a method of fractionating splanchnic blood flow using labelled sulphur colloid, and this may prove useful in the investigation of suspected chronic ischaemia.

\section{PRESENT STUDY}

Because of the lack of knowledge of the relationship between radiologically demonstrated lesions of the visceral arteries (IAO) and the symptoms and natural history of the individual patient, a prospective study of the problem was started in 1965 in the Department of Surgical Studies of The Middlesex Hospital, and the data reported here extend to January 1984.

We have, deliberately, avoided the use of terms such as 'intestinal angina', 'chronic intestinal ischaemia' or 'abdominal claudication', because such phrases assume the reality of a syndrome which it is our purpose to evaluate. Nonetheless, some sort of shorthand is useful and intestinal arterial occlusion (IAO) here refers to lesions seen on an angiogram, with no conclusions being drawn as to their clinical importance.

From 1962 to 1984 approximately 100 patients with abdominal pain were referred to The Middlesex Hospital as possible cases of intestinal arterial 
occlusion. This total is necessarily inexact, because as already reported ${ }^{8}$ a number of the patients were not investigated further and are now untraceable, either because their symptoms had disappeared when they arrived at the clinic, or because their problems did not seem in any way to resemble those related to intestinal arterial occlusion and hence were not followed up. A further group were found on investigation to have other causes of abdominal pain, as is shown in Table 1 , and were not submitted to angiography. Once these conditions had been excluded, the aorta and visceral arteries were opacified. In 21 the findings were normal. If the angiogram showed stenosis or occlusion of the main trunks (CA, SMA, IMA), it seemed ethical to submit the patient to a more exacting diagnostic procedure, in order to decide whether major surgery was justified. All patients in this series were received because of the complaint of abdominal pain, and our study does not relate to other reported series $^{8}$ where vascular operations have been carried out on patients without alimentary symptoms, but in whom intestinal arterial occlusion was incidentally discovered on an angiogram undertaken for other reasons.

\section{PATIENTS}

Table 1 shows the total group. Following the exclusions already defined, 28 patients underwent detailed investigation of their alimentary function, with a view to possible vascular surgery. This group

Table 1 Cases of IAO referred to The Middlesex Hospital, 1962-84

\begin{tabular}{|c|c|}
\hline $\begin{array}{l} \pm 100 \text { patients referred } \\
\text { with suspected } \\
\text { intestinal angina } \\
63 \text { Investigated }\end{array}$ & $\begin{array}{l} \pm 37 \text { Not investigated further } \\
\text { (Clearly unrelated problems or } \\
\text { symptoms disappeared) } \\
14 \text { found to have other pathology } \\
\text { (Gall stones, peptic ulcer, carcinoma of } \\
\text { stomach, colon or pancreas, abdominal } \\
\text { aortic aneurysm) }\end{array}$ \\
\hline 49 Aortograms & $\begin{array}{l}21 \text { no arterial lesion - not investigated } \\
\text { further }\end{array}$ \\
\hline 28 Arterial lesions & $\begin{array}{l}6 \text { no operation } \\
1 \text { refused surgery } \\
3 \text { arteritis } \\
1 \text { fibromuscular hyperplasia } \\
1 \text { unacceptable operative risk }\end{array}$ \\
\hline 22 Reconstructions & $\begin{array}{l}\text { Followed from } 6 \text { to } 120 \text { months } \\
3 \text { operative deaths } \\
2 \text { MI }(8,16 \text { days }) \\
1 \text { bowel infarct ( } 4 \text { days }) \\
2 \text { later deaths } \\
1 \text { CVA }(3 \mathrm{~ms}) \\
1 \text { bowel infarct }(9 \mathrm{~ms}) \\
15 \text { asymptomatic } \\
1 \text { unchanged } \\
1 \text { worse }\end{array}$ \\
\hline
\end{tabular}

comprised 14 men and 14 women (age range 23 to 77 years, mean age 49). They were evaluated as follows.

\section{CLINICAL APPRAISAL}

(a) Symptoms

By definition, all our patients complained of abdominal pain related to meals, and reported loss of weight and an alteration in bowel habit (either constipation or diarrhoea). Nausea and vomiting was noted in nine, and 20 gave a history relating to vascular occlusion elsewhere in the body.

\section{(b) Physical signs}

The 20 patients with arterial symptoms had objective evidence of arterial disease, as evidenced by absent lower limb pulses, or asymptomatic arterial bruits. An abdominal systolic bruit, though not always specifically sought, but was found in 14 . (The significance of this sign is in any case doubtful ${ }^{8}$ ). Apart from weight loss, there were no other relevant abnormalities on examination.

\section{(c) Baseline investigations}

Physical evaluation was followed by baseline tests comprising chest radiograph, ECG, blood film with indices and routine serum biochemistry, in order to eliminate concomitant disease and to determine fitness for possible surgery.

\section{ARTERIOGRAPHY}

In the first years of this study this was by the translumbar route. Subsequently the preferred technique was retrograde catheterisation via the femoral artery, with free injection into the aorta and selective opacification of the visceral trunks. Typical findings are illustrated in Figures 1-4.

\section{TESTS OF INTESTINAL FUNCTION}

Once an arterial obstruction had been identified, the patient was further studied with regard to intestinal function. The tests applied necessarily reflect a series which has extended over 20 years (see Table 2 ), and nowadays would be somewhat different. The following functions were investigated:

\section{(a) Iron metabolism and $B_{12}$ absorption}

This comprised serum iron concentration $(\mathrm{Fe})$, total iron binding capacity (TIBC), $\mathrm{B}_{12}$ and folate levels, Schilling test for $\mathrm{B}_{12}$ absorption.

\section{(b) Fat metabolism}

This comprised serum $\beta$-lipoprotein and fasting triglyceride concentrations, mean daily faecal fat excretion over five days, and also serum carotene concentrations which have been reported in the 


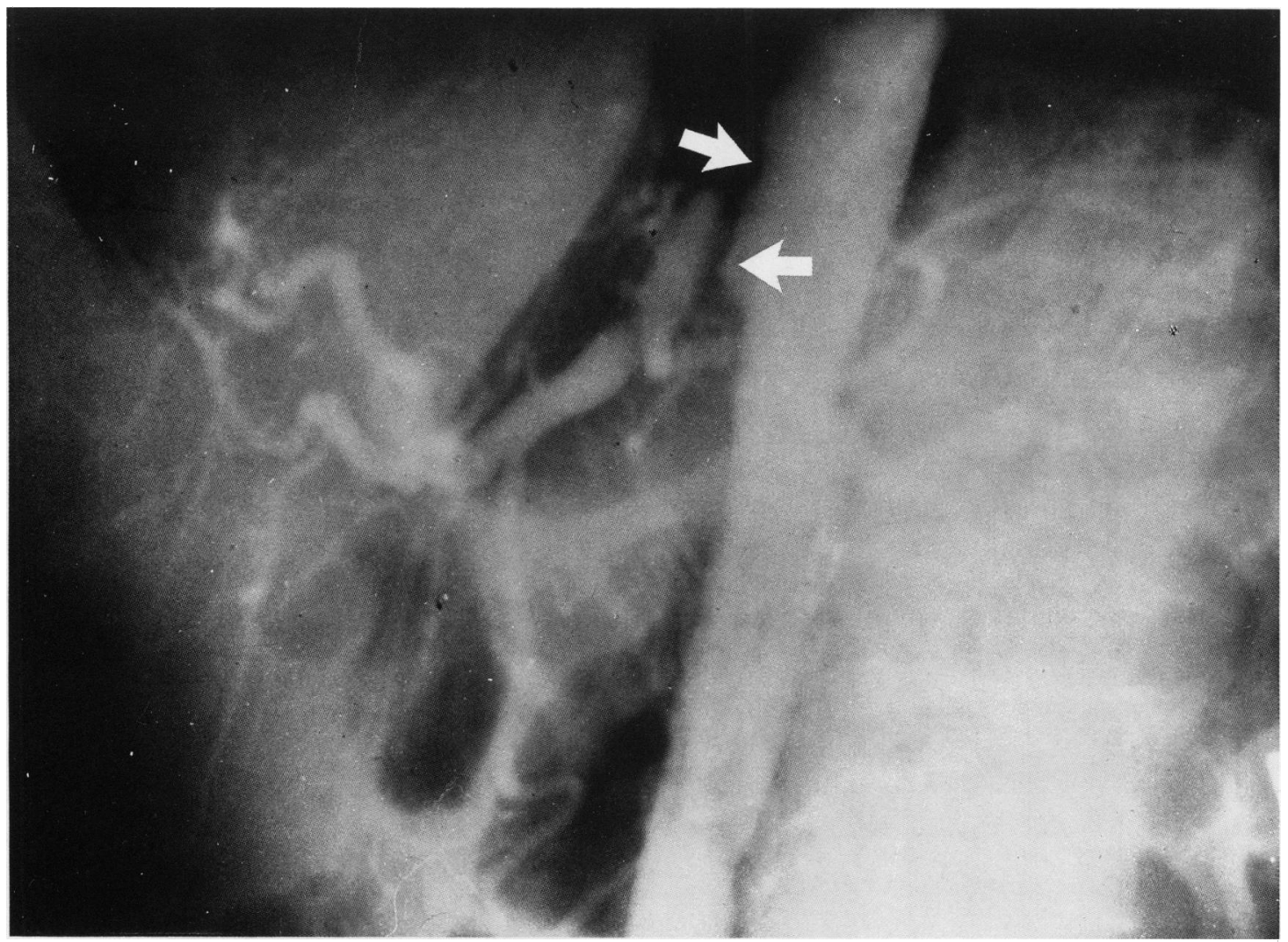

Fig. 1 Stenosis of the coeliac axis with occlusion of the superior mesenteric artery.

past, ${ }^{10132122}$ as reflecting malabsorption of vitamin $\mathrm{A}$ in chronic intestinal ischaemia.

\section{(c) Liver function}

By means of serum albumen and globulin concentrations, bilirubin, alkaline phosphatase, and AST.

\section{(d) Carbohydrate absorption and metabolism}

Comprising random blood glucose concentration, glucose tolerance test (GTT) following a $50 \mathrm{~g}$ dose and d-xylose excretion after a $5 \mathrm{~g}$ dose.

\section{(e) Intestinal protein loss}

By measurement of faecal activity, following an I/V dose of $\mathrm{Cr}^{51}$ labelled albumen.

\section{(f) Barium studies}

These were initially by conventional upper GI series, later by the intubated duodenal technique.

\section{(g) Imaging}

The series was begun before fibrendoscopy of the alimentary tract, or ultrasound examination, were easily available, but later patients were studied with these techniques.

\section{Results}

The results of these studies are set out in Table 2. It will be seen that the great majority of patients had normal absorptive and exsorptive function as measured by the tests used. Abnormalities did occur (deficient fat absorption in two, carbohydrate absorption in four and an exudate protein-losing enteropathy in two) but these were sporadic and bore no consistent relation either to the patients' symptoms, nor to the arterial lesion. Because of this, it seemed pointless to repeat the tests after operation.

As in all previous case series, management was decided on clinical criteria as no laboratory test gave sufficient discrimination. In practice this meant that significant intestinal arterial occlusion - that is, that requiring operation - was identified by exclusion, so 


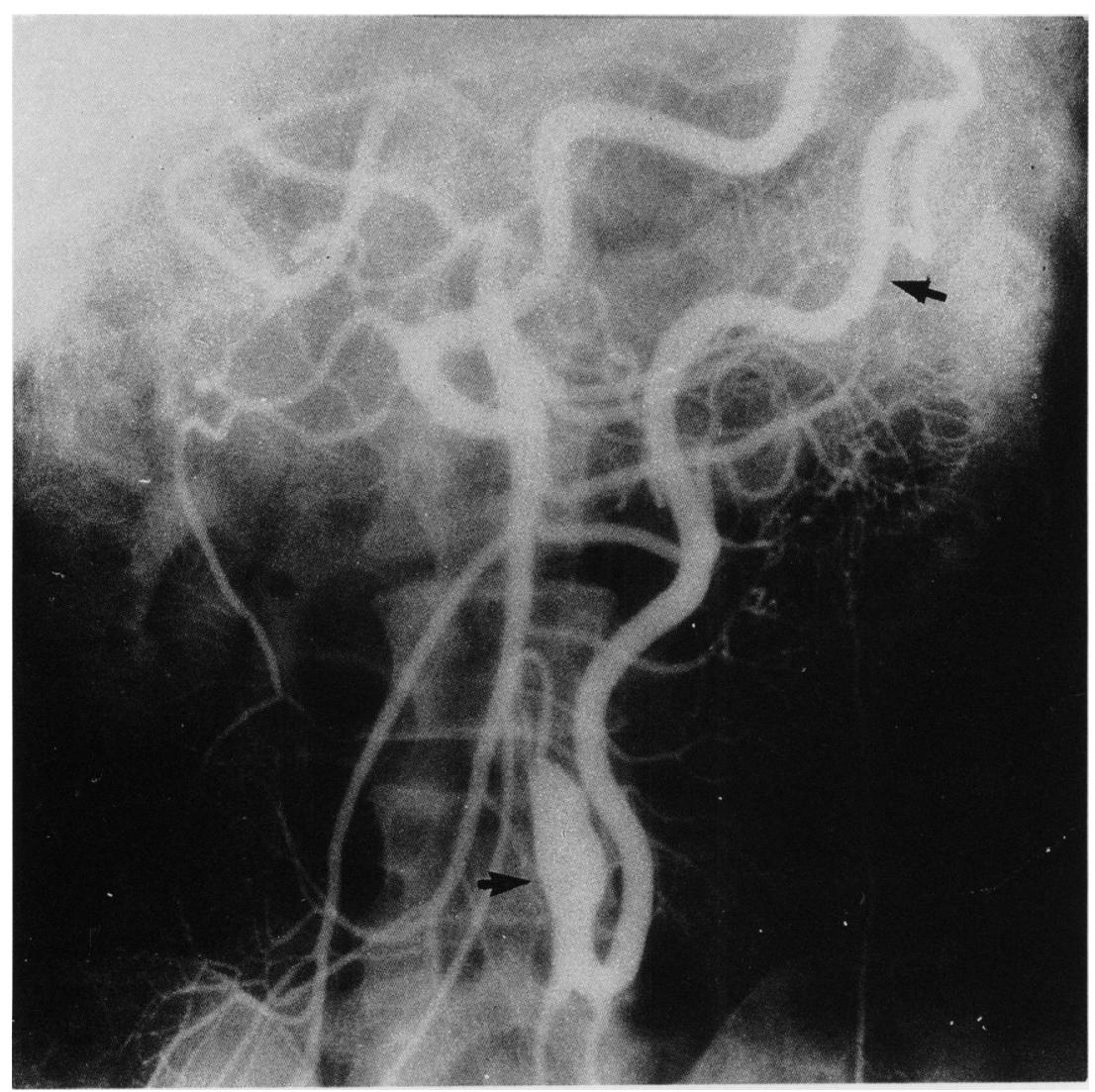

Fig. 2 Coeliac and superior mesenteric occlusion with stenosis of the inferior mesenteric artery.

that only those patients who continued to complain of pain in the presence of a known arterial block, when a full clinical assessment had not produced any other explanations, were submitted to reconstructive surgery.

The types of operation used are set out in Table 2 and illustrated in Fig. 5. Case 1 was operated upon by Mr Ian Ranger and reported ${ }^{23}$ in 1962 . The remaining operations were carried out by the principal authors (AM:20, JMFC:2). Side-to-side anastomosis between the aorta and the SMA was performed in six cases (Fig. 6). This technique has the advantage of being possible through a purely abdominal approach. Patch angioplasty of the CA, SMA or both was chosen in 10 cases, and reimplantation of the SMA in one. For these procedures a full thoraco-abdominal incision is preferred. In two patients all that was necessary was to free the origin of the CA from the surrounding tough fibrous tissue including the median arcuate ligament of the diaphragm and sympathetic and lymphatic fibres. In each case a gradient was measured across the arterial lesion, which was abolished by the procedure. In one case a tight stricture of the IMA was corrected by a Dacron patch. It was not considered justified to carry out routine postoperative angiograms, until late in the series when a digital facility became available and it was possible to opacify the visceral arteries using an intravenous injection. In the four cases so studied, three reconstructions were patent and in one an occluded graft was accompanied by return of symptoms. It will be seen that of the patients operated on three died in the immediate postoperative period, one six months later from a stroke, and one nine months later, because of total infarction of the midgut requiring enterectomy, which was followed by a fistula. Of the remainder, 13 were free of symptoms for variable periods, two were unchanged and one was substantially worse (this poor result was considered to be because of an error in psychological assessment before the operation). The follow up period is given in each case and 


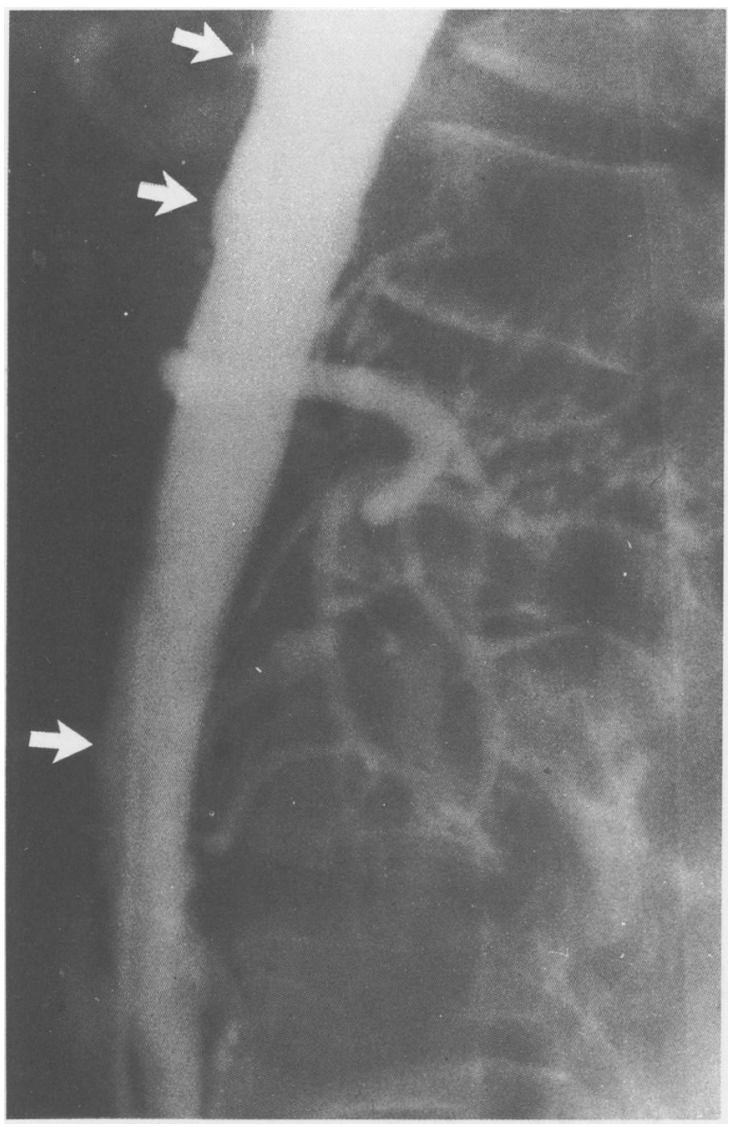

Fig. 3 Triple vessel occlusion.

ranges from six months to 10 years.

As already explained, because of the unreliable correlation of preoperative tests of intestinal function with symptoms and radiological findings, there seemed no point in repeating these costly and uncomfortable examinations, following surgery. Our results are therefore assessed symptomatically, and the defects of this approach are admitted. The only objective criterion of improvement is recovery of lost weight, which occurred in 13 patients. Two fatal intestinal infarcts occurred in the operative group, but this must be viewed against the fact that the incidence of infarction in untreatable intestinal arterial occlusion is yet to be discovered. Whereas, of course, it is well established that gut necrosis is often preceded by postcibal abdominal pain. ${ }^{82}$ The improvement in quality of life in those patients with patent reconstructions was, however, most impressive, and although they are difficult to identify, such people can be enormously benefited by appropriate surgery. The operations are exacting but recovery is on the whole smooth and free of complications. In particular we have not encountered haemorrhage from suture lines, graft or wound infection, pulmonary embolus or wound dehiscence in any of our surgically treated cases.

\section{Discussion}

The diagnosis of intestinal ischaemia remains a challenge, Dunphy in $1936^{24}$ showed that seven out of 12 patients dying from acute occlusion of the superior mesenteric artery have a prodromal history of abdominal pain. Others 812142526 have reported that asymptomatic patients with occluded main visceral arteries may be precipitated into acute intestinal infarction by a fall in central arterial pressure, however caused. Some surgeons therefore favour prophylactic correction of any such occlusion seen on an angiogram, whilst others would only operate on those who are symptomatic.

Clearly, diagnostic tests which could accurately identify the patient who is at risk of infarction would be valuable. Arteriography reveals the vascular lesion, but the clinical relevance of such appearances are not certain enough to allow a surgical

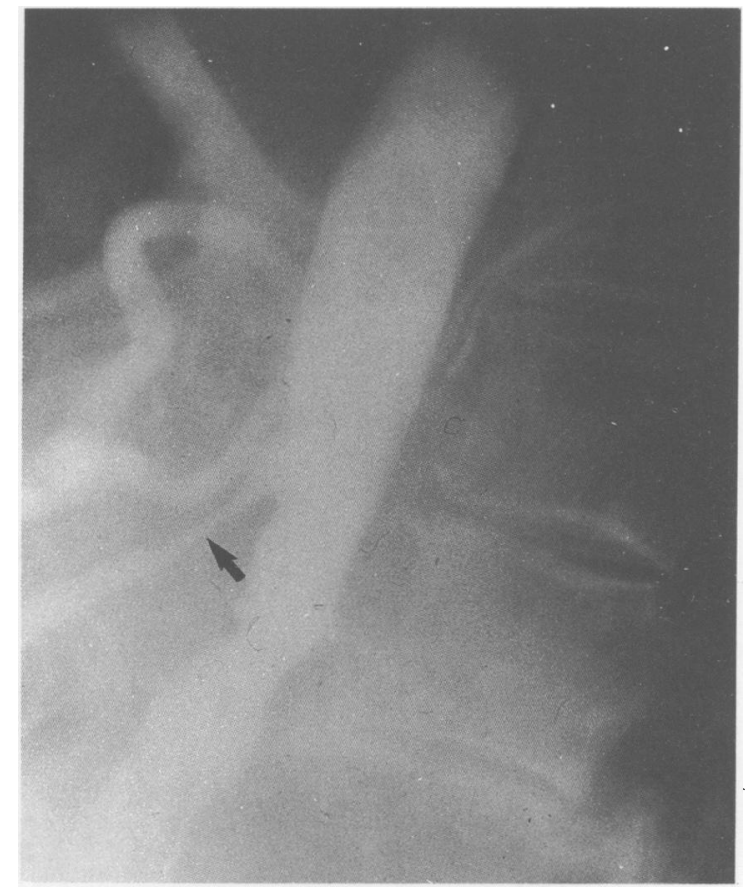

Fig. 4 Carcinoma of the pancreas, showing $C A$ obstruction and SMA stenosis. 


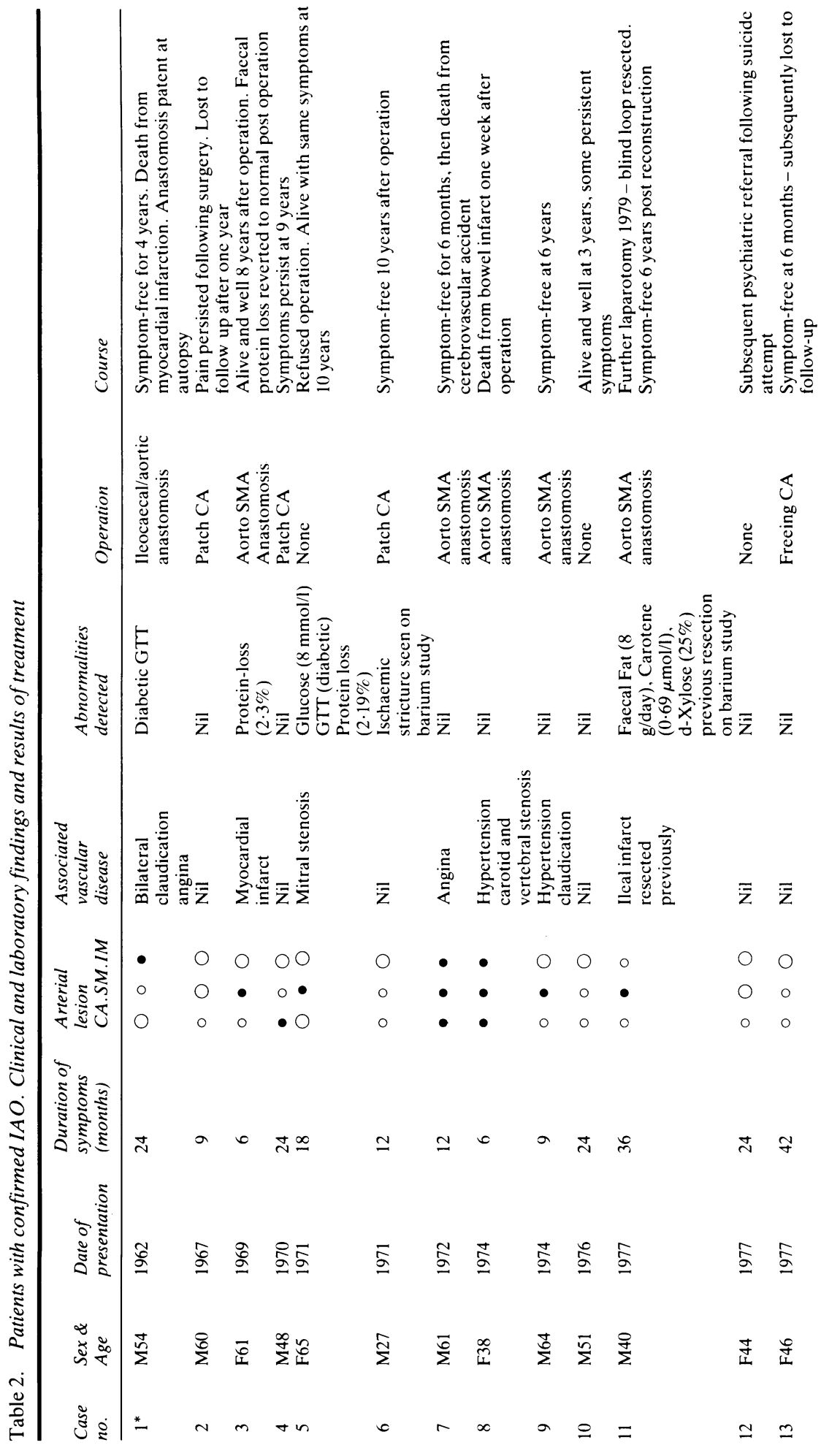

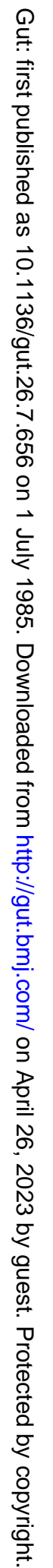



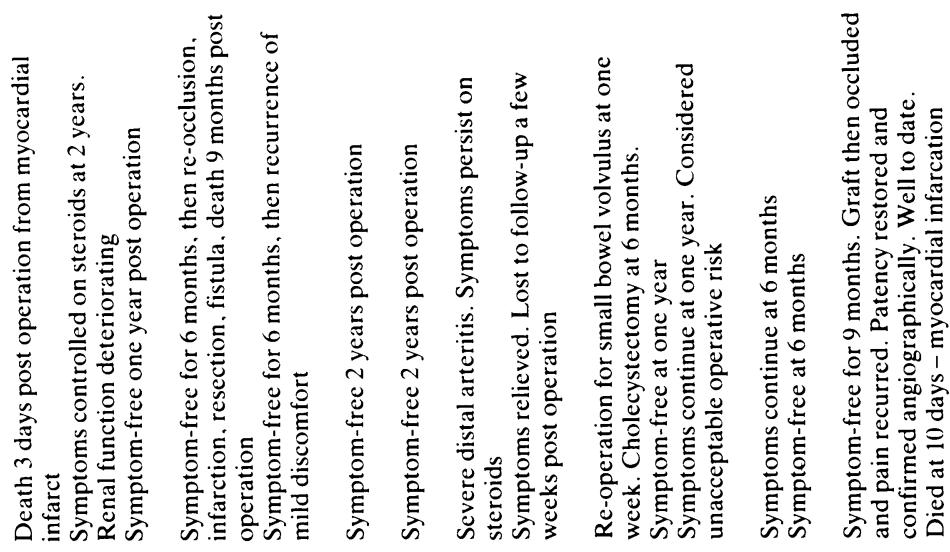

$\stackrel{\bigodot}{\rightleftharpoons}$

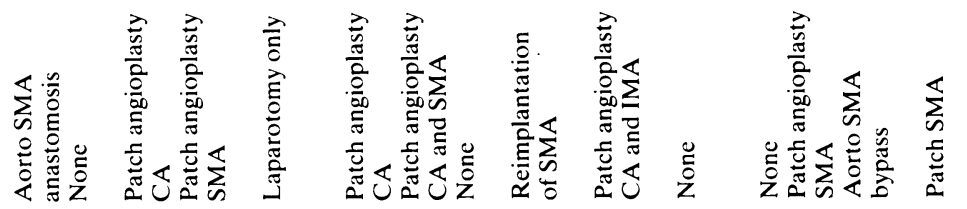

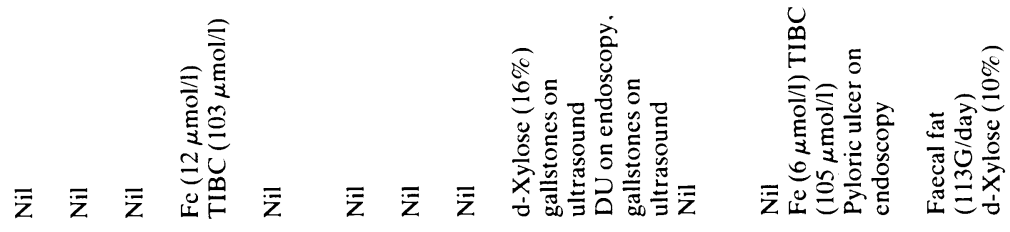

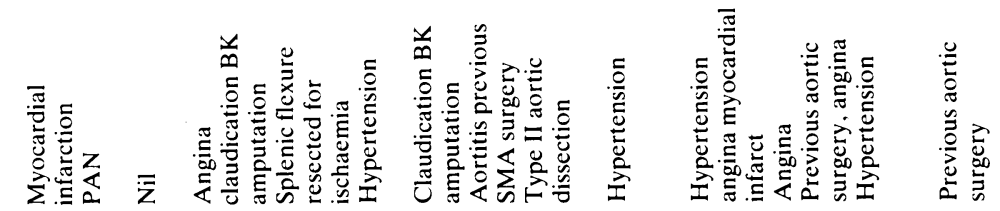

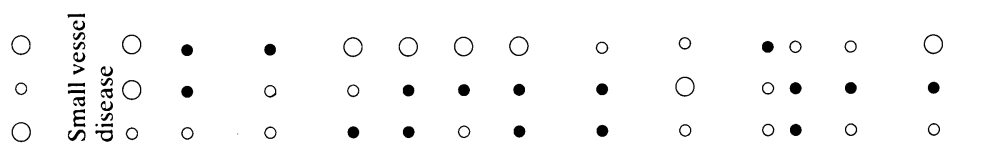

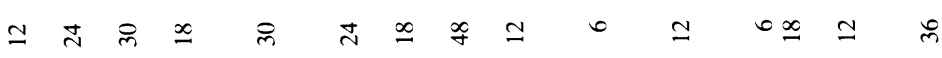

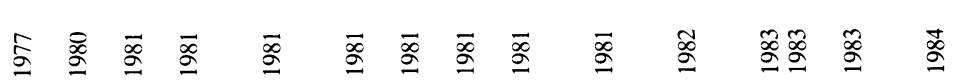

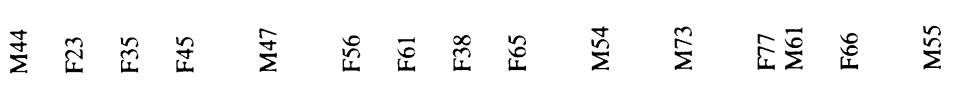

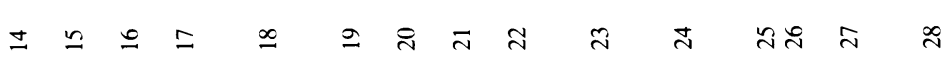




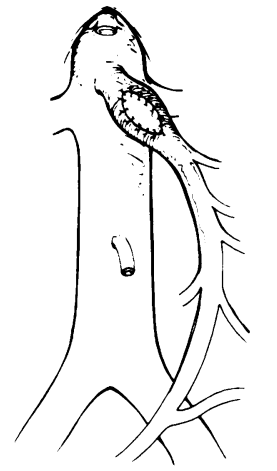

External endarterectomy \pm patch

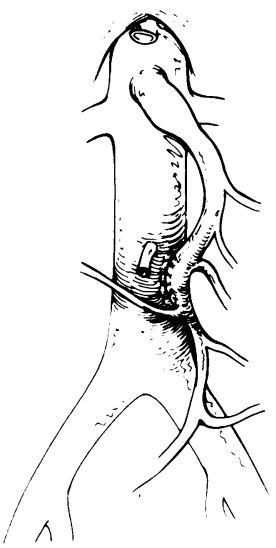

Side to side aorto-SMA anastomosis
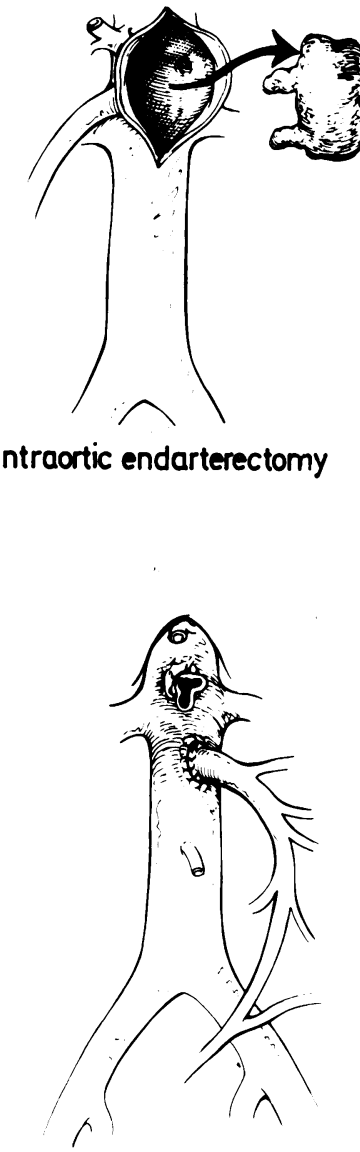

Reimplantation

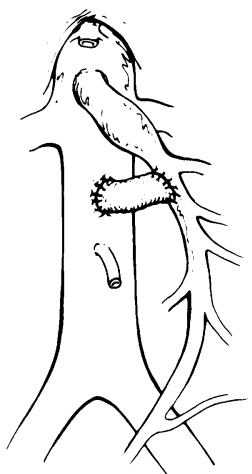

Bypass

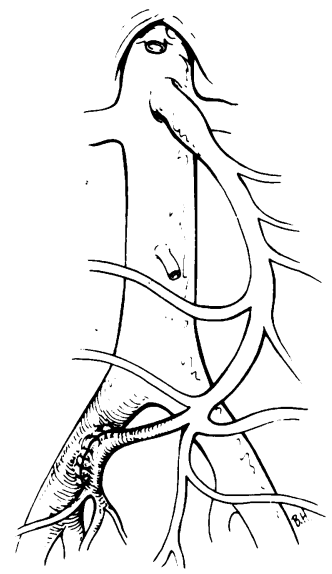

Retrograde vascularisation decision to be made. This is because asymptomatic intestinal arterial occlusion is common ${ }^{325}$ and how much it constitutes a threat to life has yet to be decided. Almost certainly, resting blood flow in such patients is within the normal range, and the pain which some of them experience after eating represents failure of the gut to produce the hyperaemia which the processes of propulsion and diges- tion require. This would equate with what is observed to happen in other vascular territories such as the heart and the legs. There is ample evidence that resting blood flow in the claudicating limb is normal, and deficiencies appear only when the circulation is challenged by exercise. If the alimentary tract behaves in the same way it is not surprising that tests of intestinal function carried out in the 


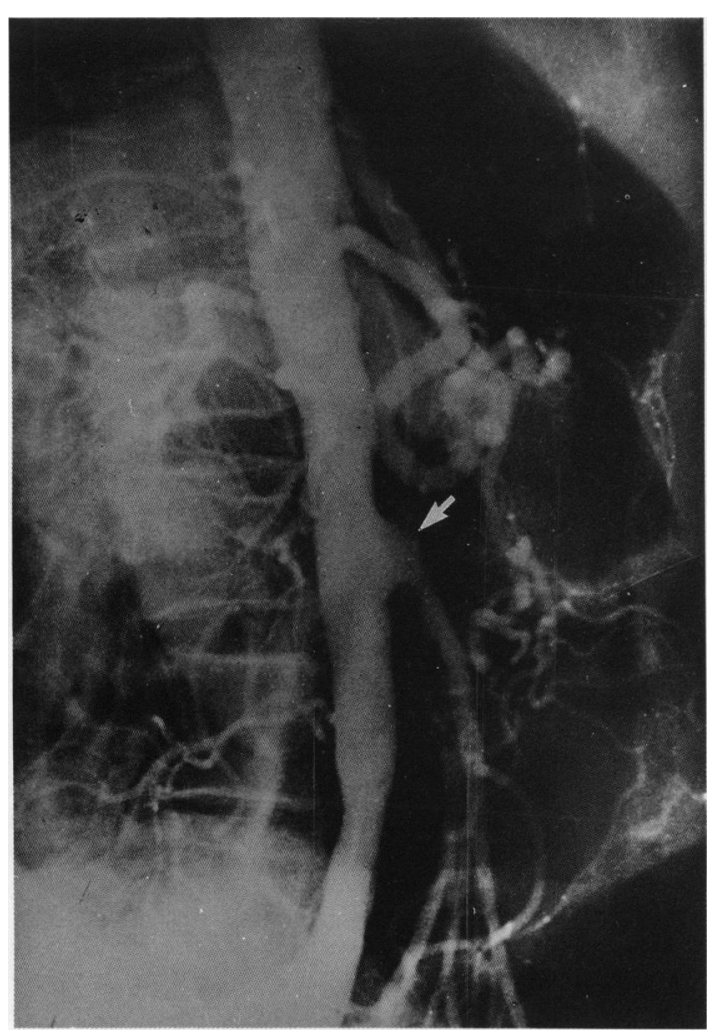

Fig. 6 Postoperative film of side-to-side aorto-SMA anastomosis, showing patent reconstruction.

resting hospital patient are unremarkable, even given gross mesenteric arterial occlusion.

By means of various compensatory mechanisms to redistribute blood flow in the wall, the absorptive area appears capable of working well up to near the point of irreversible damage. Because of available collateral circulation (particularly in the coeliac and inferior mesenteric territories) major occlusion in the visceral arteries can be compensated, to the extent that the gut is not ischaemic and no symptoms occur. This compensation may additionally be effected by internal switching mechanisms at submucosal or mucosal level, ${ }^{23}$ and by the operation of the counter current exchange mechanism within the villus. ${ }^{27}$ In any event, the tips of the villi which are the main absorptive area only receive some $8 \%$ of total flow. As arterial input is still further reduced, then pain arises from the ischaemic muscle which does not receive the increased flow required by peristalsis, but mucosal flow is preserved and insorptive/exsorptive capacity remains impaired. Hensen et $a^{5}$ showed that total splanchnic flow rises in (arteriographically) normal subjects after a meal, and that this rise fails to occur in patients with intestinal arterial occlusion, but can be restored by suitable surgery.

As vascular disease progresses, resting flow eventually falls below the level required to maintain the mucosal defences against osmolar and bacterial challenge, and infarction (focal or massive) results. One might postulate four stages: (0) normal; (1) an arterial lesion is present, but compensated, so that both resting and post-cibal flow are unimpaired, and there are no symptoms; (2) the arterial disease has progressed to the point where resting flow is normal but reactive hyperaemia cannot occur. This is signalled by the occurrence of postcibal pain; (3) The blood supply is so deficient that resting flow is reduced and perhaps minor impairments of cellular function and small, focal infarcts are occurring. This is analogous to 'rest pain' in the ischaemic limb; (4) the bowel in infarcted.

It is the identification of stage 3 which has been the object of so much clinical and laboratory endeavour over the last 80 years, since Schnitzler ${ }^{28}$ first postulated the concept of 'abdominal claudication', and it must be admitted that little progress has been made. Many authors have commented that tests of intestinal function have little predictive value, though no formal prospective study has up till now been carried out. Nonetheless, it has often been stated that chronic intestinal arterial occlusion is associated with malabsorption. Our data suggest that this is not the case, and that the weight loss which occurs is because of diminished intake. Quite different, of course, is the patient who sustains an acute ischaemia and is rescued by emergency surgery from a threatened infarction. Here the bowel is seriously damaged, perhaps by liberated superoxide radicles ${ }^{29}$ and a prolonged period of malfunction follows ${ }^{810}$ while the mucosa regenerates.

To return to the questions posed in the introduction, it is possible to claim, in the light of our experience and that previously reported, that reduction in blood supply to the gut can give rise to symptoms before infarction occurs, but these are of a variable and inconstant nature and difficult to identify. They tend to occur in an age group where other causes of abdominal pain abound, many of them more easily treated, and it is important to exclude these before deciding on a vascular origin for the pain. Moreover, arterial occlusions can occur without symptoms and probably without influencing blood flow, and can coexist with or be the result of, malignant tumours (Fig. 4).

The syndrome of intestinal angina is rare, and the academic interest which it has aroused is not entirely 
justified. This is shown by the fact that a unit particularly interested in the problem and having wide sources of referral, but using strict criteria, has authenticated only 28 cases in 20 years. Hertzer ${ }^{9}$ and Rogers $^{30}$ report a similar experience.

No non-invasive test is of use in identifying such a patient, nor in predicting who is at risk from infarction. It is occasionally possible to relieve abdominal pain and restore weight loss by reconstructing the visceral arteries, and in the most favourable cases this can be a spectacularly successful surgical exercise. These ambitious operations are not devoid of risk, however, even in centres accustomed to carrying them out. It is likely that failures are under reported.

For the future, what is needed is a simple non-invasive method of measuring intestinal blood flow before and after challenge, which can be correlated with the results of the non-invasive radiological methods now available.

\section{References}

1 Dick AP, Graff R, Gregg McC, Peters N, Sarner R. Arteriographic study of mesenteric arterial disease. Gut 1967; 8: 206-20.

2 Matz EM, Khan PC. Occlusion of the celiac, superior mesenteric and inferior mesenteric arteries. Angiographic demonstration in an asymptomatic patient. Vasc Dis 1968; 5: 130.

3 Croft RJ, Menon GP, Marston A. Does intestinal angina exist? A critical study of obstructed visceral arteries. Br J Surg 1981; 68: 316-8.

4 Lorsen RO, Lindenauer SM, Stanley JC. Splanchnic arteriosclerotic disease and intestinal angina. Arch Surg 1980; 115: 497-501.

5 Hansen HJB, Engell HC, Ring-Larsen H. Splanchnic blood flow in patients with abdominal angina before and after arterial reconstruction. Ann Surg 1977; 186: 216-20.

6 Marston A. Patterns of intestinal ischaemia. Ann $R$ Coll Surg 1964; 35: 151-81.

7 Stanley JC, Brink BE, Fry WJ. Experimental intestinal ischemia. Provocative absorption studies. J Surg Res 1973; 14: 133-8.

8 Marston A. Intestinal ischaemia. London: Edward Arnold, 1977.

9 Hertzer MR, Beven IG, Humphries AW. Chronic intestinal ischemia. Surg Gynecol Obstet 1977; 145: 321-8.

10 Joske RA, Shamma'a MH, Drummey GD. Intestinal malabsorption following temporary occlusion of the superior mesenteric artery. Am J Med 1958; 25: 449-55.

11 Shaw RJ, Maynard EP. Acute and chronic thrombosis of the mesenteric arteries associated with malabsorption. A report of two cases successfully treated by thromboendarterectomy. $N$ Engl J Med 1958; 258:
874-8.

12 Marston A, Kieny R, Szilagyi DE, Taylor GW. Intestinal ischemia. Arch Surg 1976; 111: 107-12.

13 Tilson DM, Stansel HC. Intestinal absorption eight years after successful mesenteric revascularisation. Am J Surg 1976; 131: 366-8.

14 Brandt LJ, Boley SJ. Ischemic intestinal syndromes. Adv Surg 1981; 15: 1-45.

15 Morgan RJ, Russell RI, Imrie CW, Pollock JC. Chronic small bowel ischaemia presenting as chronic pancreatitis. Postgrad Med J 1982; 58: 121-2.

16 Rampal R, Delmont J. La malabsorption d'origine Ischémique: existe-t-elle? Chir Artères Dig. Paris: Expansion Scientifique, 1975: 11-23.

17 Zelenock GB, Graham LM, Whitehouse WM et al. Splanchnic arteriosclerotic disease and intestinal angina. Arch Surg 1980; 115: 479-501.

18 Hollier LH, Bernatz PE, Pairolero PC, Payne WS, Osmundson PJ. Surgical management of chronic intestinal ischemia. Surgery 1981; 90: 940-6.

19 Crawford ES, Morris GC, Myhre HO, Roehm JOF. Celiac axis, superior mesenteric artery and inferior mesenteric artery occlusion: surgical considerations. Surgery 1977; 82: 856-66.

20 Fleming JB, Humphries NLM, Karran SJ, Goddard BA. In vitro assessment of hepatic arterial and portal venous components of liver perfusion: concise communication. J Nucl Med 1981; 22: 18-21.

21 Dardik H, Seidenberg B, Parker JC, Hurwitt ES. Intestinal angina with malabsorption treated by elective revascularisation. JAMA 1965; 194: 1206-210.

22 Webb WR, Hardy JD. Relief of abdominal angina by vascular graft. Ann Intern Med 1962; 57: 289-94.

23 Ranger I, Spence MP. Superior mesenteric artery occlusion treated by ileocolic anastomosis. $\mathrm{Br} \mathrm{Med} \mathrm{J}$ 1962; 2: 95-6.

24 Dunphy JE. Abdominal pain of vascular origin. Am J Med Sci 1936; 192: 109-12.

25 Reiner L, Jimenez FA, Rodriguez FL. Atherosclerosis in the mesenteric circulation. Am Heart J 1963; 66: 200-9.

26 Eidemuller LR, Nelson JC, Porter JM. Surgical treatment of chronic visceral ischemia. Am J Surg 1979; 138: 264-8.

27 Mailman D. Blood flow and intestinal absorption. Fed Proc 1982; 41: 2096-100.

28 Schnitzler J. Zur symptomatologie des darmarterien verschlusses. Munsch Med Wochenschr 1901; 98: 552.

29 Parks DA, Bulkley GB, Granger DN, Hamilton SR, McCord JM. Ischemic injury in the cat small intestine: role of the superoxide radicals. Gastroenterology 1982; 82: 9-15.

30 Rogers DM, Thompson JE, Garret WV, Talkington CM, Patmen RD. Mesenteric vascular problems. A 26 year experience. Ann Surg 1982; 195: 554-65.

31 Reul GJ, Wukasch C, Sandiford FM, Chiarillo L, Hallman GC, Cooley DA. Surgical treatment of abdominal angina. Review of 25 patients. Surgery 1974; 75: $682-9$.

32 Granger DN, Richardson PDI, Kvietys PR, Mortarillaro NA. Intestinal blood flow. Gastroenterology 1980; 78: 837-63. 